\title{
FLOOD MAPPING AND PERMANENT WATER BODIES CHANGE DETECTION USING SENTINEL SAR DATA
}

\author{
R. Nasirzadehdizaji ${ }^{1, *}$, D. E. Akyuz ${ }^{1}$, Z. Cakir ${ }^{2}$ \\ ${ }^{1}$ Dept. of Civil Engineering, Engineering Faculty, Istanbul University, 34320 Avcilar, Istanbul, Turkey - \\ rouhollahn@ogr.iu.edu.tr, dilek.akyuz@istanbul.edu.tr \\ ${ }^{2}$ Dept. of Geology, Faculty of Mines, Istanbul Technical University, 34469 Maslak, Istanbul, Turkey - ziyadin.cakir@itu.edu.tr
}

KEY WORDS: Sentinel-1and -2, SAR, SWIR, Image Processing, Flood Mapping, Flood Risk Management, Change Detection

\begin{abstract}
:
Producing flood maps that can be carried out quickly for disaster management applications is essential to reduce the human and socio-economic losses. In addition, mapping and change detection of water bodies as an essential natural resource is imperative for robust operations and sustainable management. Synthetic Aperture Radar (SAR) sensors with long wavelengths have a high potential for delineating the extent of the flooded areas and providing timely and accurate maps of surface water for risk mitigation and disaster or sustainable management. In this study, multi-temporal Sentinel-1 C-band SAR images were utilized to investigate the performance of the sensor backscatter image on permanent water bodies monitoring and flooded areas mapping. Lake Urmia as a permanent water system and two floods in Golestan and Khuzestan provinces of Iran have been investigated. The backscatter values of an image acquired before the event that is referred as an Archive image and another one after the event as a Crisis image are analysed. As a preliminary result, it is concluded that with overlaying of the two bands from Archive and Crisis images and creating a color composite image, the permanent water bodies have a uniformly dark return due to the very low backscatter in both images. The flooded areas and changes in water level show relatively higher backscatter in the Crisis image, whereas the other land cover features indicate very high backscatter values with tones of grey. Therefore, Sentinel-1 SAR data provides beneficial information on flood risk management and change detection.
\end{abstract}

\section{INTRODUCTION}

Management of water resources due to the increasing demands, scarcity of resources, socio-economic impacts and other factors has gained widespread currency in terms of sustainable management. Increasing flood risks due to climate change are the subject drawn attention in the context of sustainability of vital ecosystems. Timely and accurate mapping of surface water bodies' changes detection and extraction of flooding extent over large geographical areas from satellite imagery has been widely applied in recent years (Clement, 2017). Images obtained in the optical spectrum from multi-spectral sensors due to their straightforward interpretability are preferred data source in the case of favourable weather conditions. However, during the persistent and long-lasting period of cloud cover in the rainy season, the use of optical sensors are limited for the continuous monitoring of the flood disaster and the surface water bodies' change detection (Bioresita, 2018). Synthetic Aperture Radar (SAR) system is as a widely used, practical and efficient tool in such applications due to collection of data in day-or-night and in different weather conditions with a constant observation of earth surface from the polar orbit (Soria-Ruiz, 2009).

For the last two decades, with development of space-borne SAR technology due to its unique imaging capabilities has been made it most appropriate tool for large-scale flood mapping, operational flood relief management and for monitoring water bodies (Mason, 2013). Various change detection methods and flood extent mapping techniques based on multi-temporal SAR images are used for disaster monitoring and management (e.g. Martinez, 2007, Martinis, 2010, Giustarini, 2014, Dasgupta,
2018). Application of microwave remote sensing has increased for the flood extent prediction, flood monitoring in the crucial, small and large-scale, and operational scenarios due to the SAR sensors high spatial (e.g. TerraSAR-X with higher spatial resolution up to $0.24 \mathrm{~m}$ ) and temporal resolutions (e.g. Sentinel1 series with six-day revisit times) (Bioresita, 2018). Ramsey (1995) utilized ERS-1 SAR images to distinguish flooded from non-flooded black needlerush marsh and map out tidal flood extent. Martinis (2014) introduced TerraSAR-X based flood service to the dispersion of the flood masks in emergency cases. The potential of the X-band SAR COSMO-SkyMed system for flood detection is illustrated by (Pierdicca, 2012). Harmonic model analysis from multi-temporal ENVISAT Advanced SAR (ASAR) data is applied by (Schlaffer, 2015) with characterising normal backscatter behaviour of the ASAR image time-series to flood mapping and change detection.

Among the various microwave satellites, Sentinel-1 with high spatial and temporal resolutions has convinced scientists and decision makers to its systematic application for disaster monitoring and management. Sentinel-1 satellites are designed to operate in a pre-programmed conflict-free processing mode, covering the global ocean and landmasses, a constellation in the same orbital plane with a consistent long-term data archive based on long time series applications (Torres, 2012). During the flood events, time is one of the main factors to flood management activities in terms of minimizing the time delay between data delivery and product dissemination (Twele, 2015). Hence, Sentinel-1 data can provide continuous and frequent information about the flood extent to enhance supports and services for the most part of the globe. For a quick flood

\footnotetext{
* Corresponding author
} 
mapping, an automatic change detection method based on Sentinel-1 SAR data is presented by $(\mathrm{Li}, 2018)$. This is more effective, flexible and robust method in computation time in case of highly unbalanced datasets. In order to increase the change detection results, they also introduced an algorithm to remove noise and to maintain detailed information at the same time. The similar work has been done by (Bioresita, 2018) for end-users quickly mapping of water surfaces and flood detection based on Sentinel-1 amplitude data and they resulted with high overall accuracies. Hardy (2019) has introduced a new approach for extraction of both vegetated and open water bodies in Western Zambia using sequential Sentinel-1 imagery. It is found that Sentinel-1 radar signals enable to detect open water surfaces and vegetated water bodies with mostly dispersed grasses with height less than $20 \mathrm{~cm}$ in a large floodplain whereas Sentinel-1 is limited for denser vegetated water bodies and floodplains.

In this study, we map flooded areas and the water bodies' changes using Sentinel 1 SAR data in north and western Iran. Multi-temporal SAR data analysis is conducted to discriminate flooded areas over the permanent water bodies and to produce reliable and accurate maps of surface water.

\section{MATERIALS AND METHODOLOGY}

\subsection{Study Area: Iran}

Lake Urmia $\left(37^{\circ} 42^{\prime} \mathrm{N}, 45^{\circ} 19^{\prime} \mathrm{E}\right)$, Golestan province $\left(36^{\circ} 50^{\prime} \mathrm{N}\right.$, $\left.54^{\circ} 25^{\prime} \mathrm{E}\right)$ and Khuzestan province $\left(31^{\circ} 19^{\prime} \mathrm{N}, 48^{\circ} 40^{\prime} \mathrm{E}\right)$ are three different areas where flooding has taken place recently in Iran (Figure 1). Determination of surface water level change of the Lake Urmia requires attention due to its socio-ecological and environmental issues. Moreover, considering the two floods with plenty of damage in Golestan and Khuzestan provinces in consequence of the high and extensive rainfalls has motivated us to carry out this study.

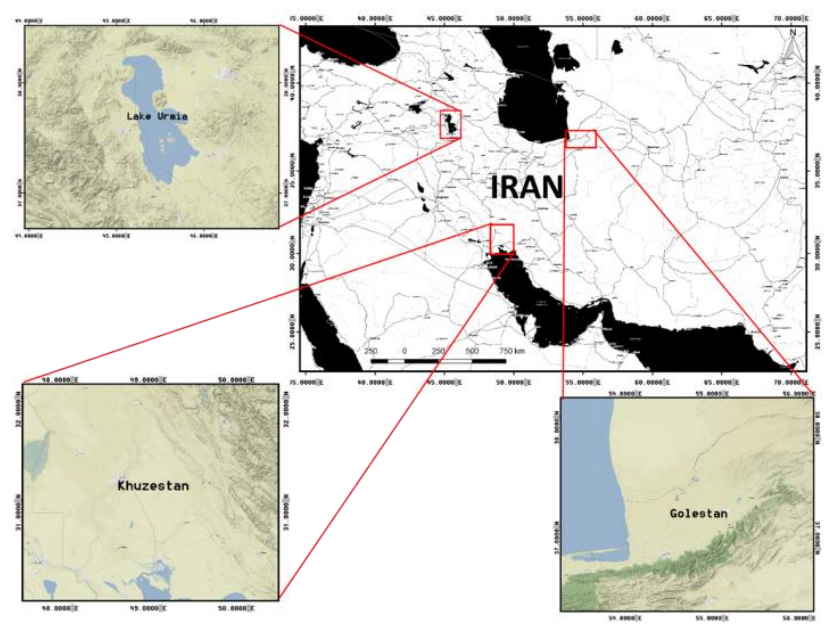

Figure 1. Location maps of the test areas

\subsection{Data statement and image processing}

SAR technique using Sentinel-1 C-band data was applied with a combination of an image acquired during the flood with an image applied before the flood to distinguish between flooded areas and permanent water bodies. In disaster mapping applications, the image acquired before the event is referred as the Archive image (i.e. reference image) and the one after the event as the Crisis image (Chesnel, 2007). According to the data availability and extent coverage of the regions during the flood events, the Ground Range Detected in High resolution (GRDH) Sentinel-1 C-band SAR products with VV (vertically transmitted vertically received) and $\mathrm{VH}$ (vertically transmitted horizontally received) polarization were acquired from the European Space Agency (ESA) Sentinels Scientific Data Hub (https://scihub.copernicus.eu/dhus/) in the Interferometric Wide (IW) swath mode. Table 1 shows the Sentinel-1 SAR data descriptions. The GRDH products are multi-looked amplitude images with no phase information and projected to ground range using an Earth ellipsoid model such as WGS84.

\begin{tabular}{|c|c|c|c|c|}
\hline \multirow{2}{*}{ Location } & \multicolumn{3}{|c|}{ Occasion } & \multirow{2}{*}{-Satellite Pass } \\
\hline & UTM Zone & Acquisition Date & Image Category & \\
\hline Khuzestan & $39 \mathrm{~N}$ & $\begin{array}{c}09 \text { March } 2019 \\
\text { 08 April } 2019\end{array}$ & $\begin{array}{l}\text { Archive } \\
\text { Crisis }\end{array}$ & $\begin{array}{l}\text { Descending } \\
\text { Descending }\end{array}$ \\
\hline Golestan & $40 \mathrm{~N}$ & $\begin{array}{l}11 \text { March } 2019 \\
23 \text { March } 2019 \\
\end{array}$ & $\begin{array}{l}\text { Archive } \\
\text { Crisis }\end{array}$ & $\begin{array}{l}\text { Descending } \\
\text { Descending }\end{array}$ \\
\hline Lake Urmia & $38 \mathrm{~N}$ & $\begin{array}{l}31 \text { August } 2017 \\
23 \text { April } 2019\end{array}$ & $\begin{array}{l}\text { Archive } \\
\text { Crisis }\end{array}$ & $\begin{array}{l}\text { Ascending } \\
\text { Ascending }\end{array}$ \\
\hline
\end{tabular}

Table 1. Specifications of obtained Sentinel-1 datasets

The GRDH images were multi-looked, calibrated and then a terrain correction using 3-arc-second SRTM was applied. In order to better visualization and manipulation the pixels were converted from a linear scale to a non-linear and to a logarithmic scale known as decibel $(\mathrm{dB})$. Pre-processing was applied using ESA Sentinel-1 toolbox (S1TBX) in the Sentinel Application Platform (SNAP) provided by ESA (SNAP Development Team, 2019). The work flow of processing of raw Sentinel-1 data is shown in Figure 2.

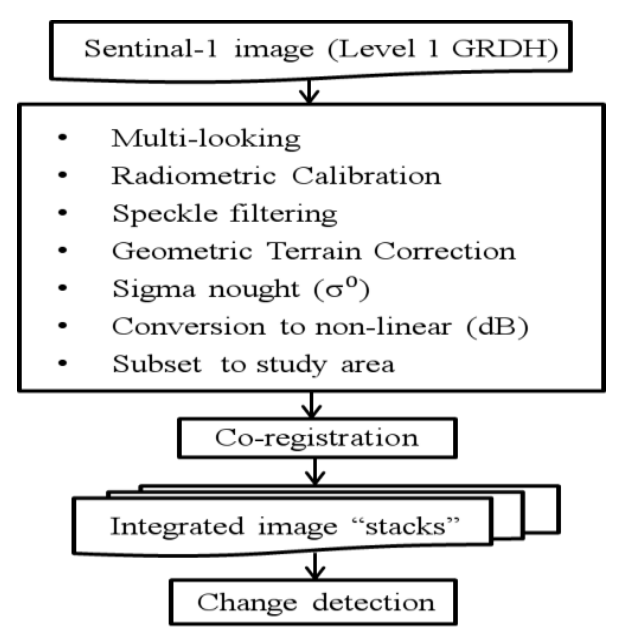

Figure 2. Flowchart of Sentinel-1 SAR data processing

In pre-processing of GRDH data, multi-looking would reduce the resolution of the image. Thereby, multi-looking is applied in case that flooded area covers large extent and low resolution is still enough for data extraction and mapping flooded areas. Sentinel-2 optical images acquired prior and right after the event when the sky is almost clean of clouds as a validation datasets of surface water (includes permanent water and flood extent) (Table 2). 


\begin{tabular}{cccc}
\hline \multirow{2}{*}{ Location } & \multicolumn{2}{c}{ Occasion } & \multirow{2}{*}{ Acquisition Mode } \\
\cline { 2 - 4 } & Acquisition Date Image Category & \\
\hline \multirow{2}{*}{ Khuzestan } & 05 February 2019 & Archive & SWIR \\
& 11 April 2019 & Crisis & SWIR \\
\hline \multirow{2}{*}{ Golestan } & 11 March 2019 & Archive & SWIR \\
& 05 April 2019 & Crisis & SWIR \\
\hline \multirow{2}{*}{ Lake Urmia } & 30 August 2019 & Archive & SWIR \\
& 27 April 2019 & Crisis & SWIR \\
\hline
\end{tabular}

Table 2. Specifications of validation datasets obtained from Sentinel-2 images

\section{RESULTS}

In SAR-based change detection analysis, it is revealed that in the crisis image the flooded area is quite obvious and appears dark as patches of low backscatter return due to the specular reflection over the smooth water surface (Figure 3). While the signals get reflected away from the flooded regions, the surrounding areas with much rougher and rugged terrain appear light owing high intensity values. In this study both $\mathrm{VV}$ and $\mathrm{VH}$ polarizations are analysed. Backscatter values for each selected pixel in flooded areas and Lake Urmia were determined and the correlation between the archive and crisis images was evaluated. In VV polarization the mean values of pixels for archive image for three different locations were $-7 \mathrm{~dB},-9 \mathrm{~dB}$ and $-10 \mathrm{~dB}$ for Khuzestan, Golestan and Lake Urmia respectively. This for crisis image were $-24 \mathrm{~dB},-21 \mathrm{~dB}$ and $-27 \mathrm{~dB}$. Figure 4 shows backscatter values of archive and crisis images for study areas.

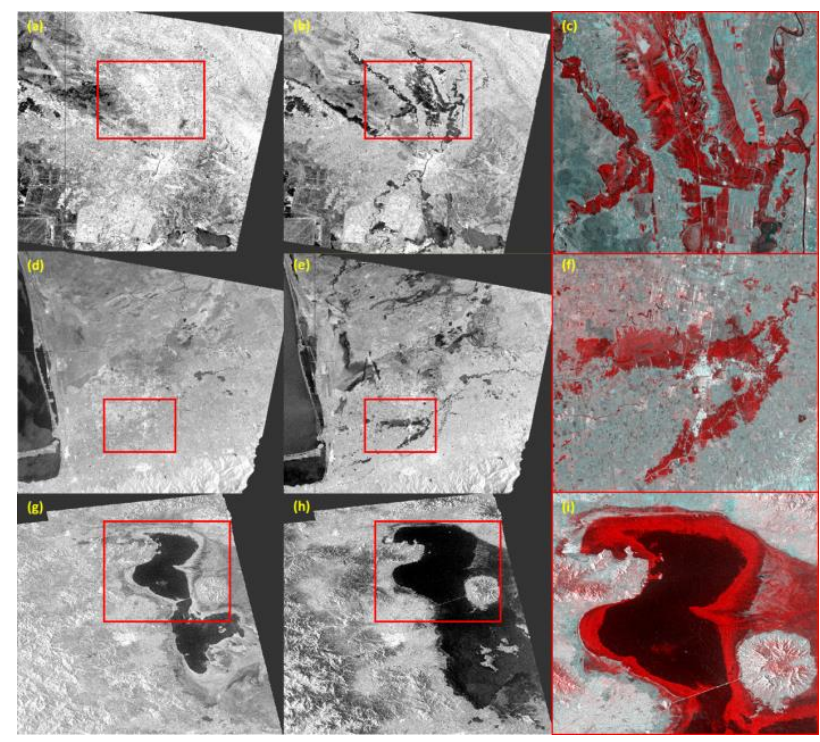

Figure 3. From left to right Archive and Crisis SAR images and the zoomed regions with a red border for the study areas. (a-c) Khuzestan, (d-f) Golestan and (g-i) Lake Urmia

The results indicate that in compared with $\mathrm{VH}$ polarization VV showed less variation and then had better interaction to discriminate flooded areas and permanent water bodies. This is probably due to the sensitivity of co-polarization (e.g. VV) over the rough water surface since backscattering in crosspolarization (e.g. VH) is generally very low (Leckie, 1998, Martinis, 2016). That brings out that in different polarization the interaction and scattering of the signals vary in respect to surface phenomena.

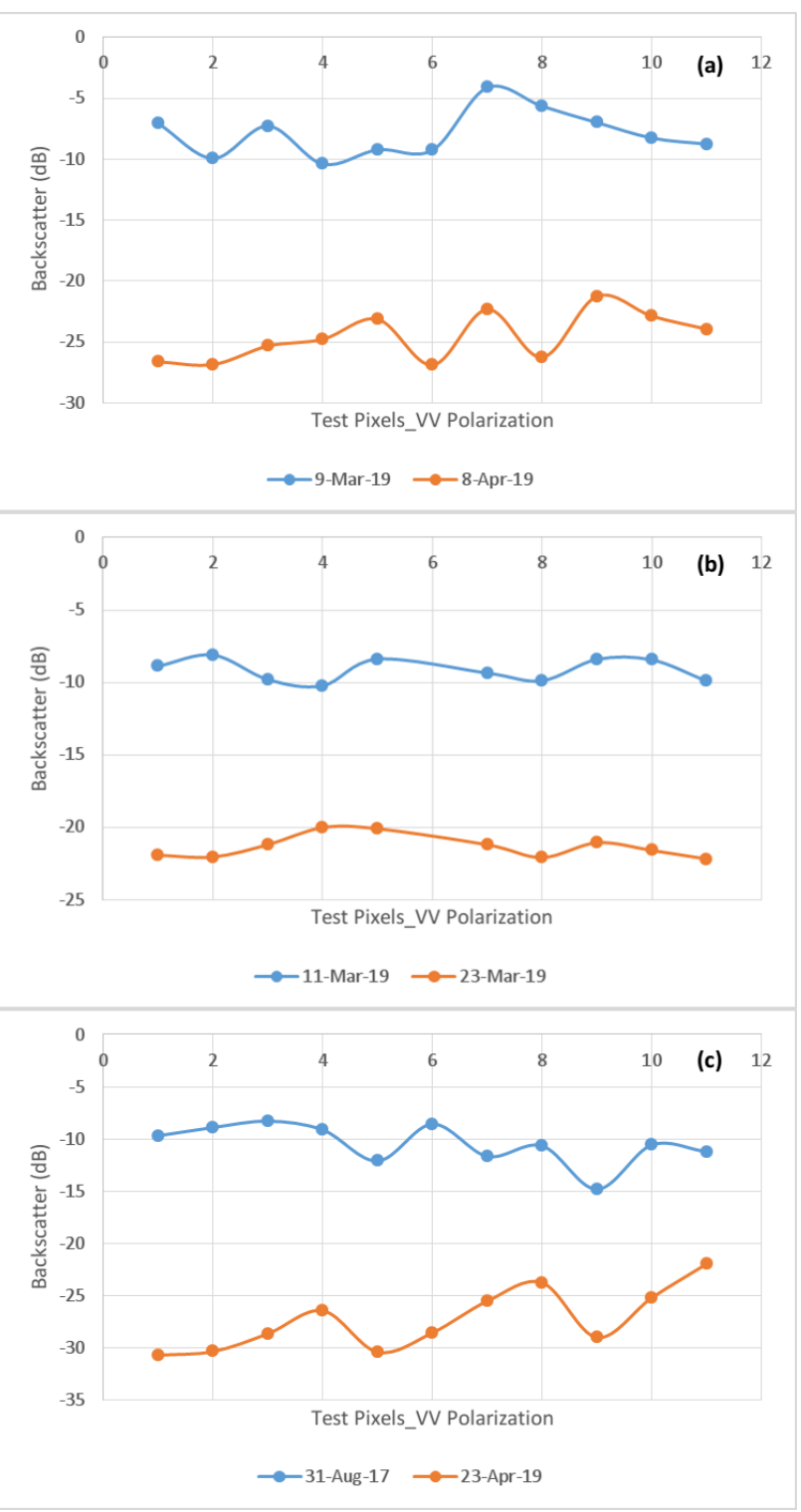

Figure 4. Backscatter values of Archive image in blue and Crisis image in orange for the study areas for VV polarization.

(a) Khuzestan, (b) Golestan and (c) Lake Urmia

Flood and surface water validation data obtained from Sentinel2 multispectral images over the study area (Figure 5). Short Wave Infrared (SWIR) multispectral band with a resolution of $20 \mathrm{~m}$ is used for validation purpose. SWIR acquisition mode enables access to information in the short wave infrared portion of the electromagnetic spectrum (ESA Communications). SWIR sensor with 1-3 $\mu \mathrm{m}$ wavelengths is capable to penetrate haze, smoke and thin clouds and due to its significant absorption by water is particularly useful to discriminate wet earth from dry earth and consequently for water detection and quantification (Stark, 2015). By visual interpretation and comparing of the Archive and Crisis images from the Sentinel-2 data in the Figure 5, the flood extent can be distinguished from the nonflooded areas in two flood affected provinces and water surface changes in Lake Urmia. 


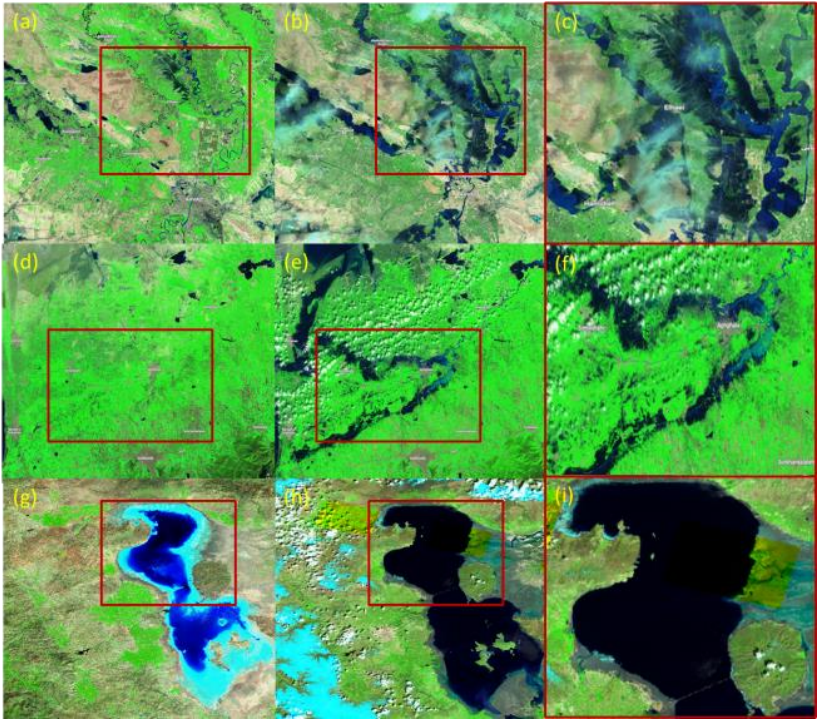

Figure 5. Optical images of the studied regions. From left to right Archive and Crisis images and the zoomed regions with a red border for the study areas. (a-c) Khuzestan, (d-f) Golestan and (g-i) Lake Urmia

\section{CONCLUSION}

SAR sensors equipping the microwave region of the electromagnetic spectrum with long wavelengths have a high potential for delineating the extent of the flooded areas and providing timely and accurate maps of surface water for risk mitigation and disaster management. In this study, Sentinel-1 SAR backscatter over the time between before and after floods in three different test areas is evaluated. In comparison with the Archive image that permanent water bodies have very low backscattering and appear dark, in the Crisis image the flooded areas and changes in water level show relatively higher backscatter and appear red. Whereas over the surrounding areas with no water present, the backscatter values are very high and these areas are observed in tones of grey. Sentinel-2 optical data also acquired prior and after the event as a validation datasets of surface water and flood extent. The flood extent was derived from the Sentinel-2 SWIR images. However, when interpreting the results of the validation it should be taken into consideration that the optical imagery was obtained when atmospheric condition was appropriate and after the SAR scene while the flood extent and consequently its affects could have changed in the meantime. Moreover, in validation against the Sentinel-1 data, SAR dataset showed high reliability of the retrieved flood probability maps and water bodies change detection. In conclusion, due to its free availability, the multi-temporal Sentinel-1 C-band SAR data provide beneficial information in flood risk management and hazard mitigation.

\section{REFERENCES}

Bioresita, F., Puissant, A., Stumpf, A., Malet, J., 2018. A Method for Automatic and Rapid Mapping of Water Surfaces from Sentinel-1 Imagery. Remote Sens. doi: $10.3390 / \mathrm{rs} 10020217$.

Chesnel, A., Binet, R., Wald, L., 2007. Damage assessment on buildings using very high resolution multimodal images and
GIS. 5th International Workshop on Remote Sensing for Disaster Management Applications. Washington, DC, United States. hal-00464860.

Clement, M. A., Kilsby, C. G., Moore, P., 2017. Multi-temporal synthetic aperture radar flood mapping using change detection. Journal of Flood Risk Management. doi: 10.1111/jfr3.12303.

Dasgupta, A., Grimaldi, S., Ramsankaran, R. A.A.J. Pauwels, V. R.N., Walker, J. P., 2018. owards operational SAR-based flood mapping using neuro-fuzzy texture-based approaches. Remote Sens. Environ. 215, 313-329. doi: 10.1016/j.rse.2018.06.019.

ESA, Copernicus Open Access Hub, 2014. European Space Agency (ESA). https://scihub.copernicus.eu/dhus/ (15 April 2019).

ESA, Sentinel-2: ESA's Optical High-Resolution Mission for GMES Operational Services, 2012. European Space Agency (ESA). SP-1322/2 March 2012.

Giustarini, L., Hostache, R., Matgen, P., Schumann, G.J., Bates, P.D., Mason, D.C., 2013. A change detection approach to flood mapping in urban areas using TerraSAR-X. IEEE Trans. Geosci. Remote Sens. 51, 2417-2430. doi:10.1109/TGRS.2012. 2210901.

Hardy, A., Ettritch, G., Cross, D., Bunting, P., Liywalii, F., Sakala, J., Silumesii, A., Singini, D., Smith, M., Willis, T., Thomas, C., 2019. Automatic Detection of Open and Vegetated Water Bodies Using Sentinel 1 to Map African Malaria Vector Mosquito Breeding Habitats. Remote Sens. 11, 593. doi:10.3390/rs11050593.

Leckie, D. G., 1998. Forestry applications using imaging radar. In Henderson, F. M., and A. J. Lewis (eds.), Manual of Remote Sensing: Principles and Applications of Imaging Radar, 3rd edn. John Wiley \& Sons, New York.

Martinez, J.M., Le Toan, T., 2007. Mapping of flood dynamics and spatial distribution of vegetation in the Amazon floodplain using multitemporal SAR data. Remote Sens. Environ. 108, 209-223. doi:10.1016/J.RSE.2006.11.012.

Martinis, S., Kersten, J., Twele, A., 2014. A fully automated TerraSAR-X based flood service. ISPRS J Photogramm Remote Sens. 104, 203-212. doi: 10.1016/j.isprsjprs.2014.07.014.

Martinis, S., Kersten, J., Twele, A., 2016. Flood Studies Using Synthetic Aperture Radar Data. Remote Sensing of Water Resources, Disasters, and Urban Studies. 3, 145-173.

Mason, D. C., Giustarini, L., Garcia-Pintado, J., Cloke, H. L., 2014. Detection of flooded urban areas in high resolution Synthetic Aperture Radar images using double scattering. INT J APPL EARTH OBS. 28, 150-159. doi: 10.1016/j.jag.2013.12.002.

Pierdicca, N., Pulvirenti, L., Chini, M., Guerriero, L., Candela, L., 2013. Observing floods from space: Experience gained from COSMO-SkyMed observations. Acta Astronaut. 84, 122-133. doi: 10.1016/j.actaastro.2012.10.034.

Ramsey, E. W., 1995. Monitoring flooding in coastal wetlands by using radar imagery and ground-based measurements. Int $\mathrm{J}$ 
Remote Sens. Vol. 16, Issue 13, 2495-2502. doi: $10.1080 / 01431169508954571$.

Schlaffer, S., Matgen, P., Hollaus, M., Wagner, W., 2015. Flood detection from multi-temporal SAR data using harmonic analysis and change detection. INT J APPL EARTH OBS. 38, 15-24. doi: 10.1016/j.jag.2014.12.001.

SNAP Development Team, 2019. Sentinel Application Platform Software (SNAP). http://step.esa.int/ main/toolboxes/snap/ (1 May 2019).

Soria-Ruiz, J., Fernandez-Ordonez, Y., McNairn, H., 2009. Corn Monitoring and Crop Yield Using Optical and Microwave Remote Sensing. Geosci. Remote Sens. 405-419. doi:10.5772/8311.

Stark, B., McGee, M., Chen, Y., 2015. Short wave infrared (SWIR) imaging systems using small Unmanned Aerial Systems (sUAS). International Conference on Unmanned Aircraft Systems (ICUAS). Denver, Colorado, USA, June 9-12, 2015.

Torres, R., Snoeij, P., Geudtner, D., Bibby, D., Davidson, M., Attema, E., Potin, P., Rommen, B., Floury, N., Brown, Traver, I., Deghaye, P., Duesmann, B., Rosich, B., Miranda, N., Bruno, C., L'Abbate, M., Croci, R., Pietropaolo, A., Huchler, M., Rostan, F., 2012. GMES Sentinel-1 mission. Remote Sens. Environ.120, 9-24. doi: 10.1016/j.rse.2011.05.028.

Twele, A., Martinis, S., Cao, W., Plank, S., 2015. Inundation mapping using C- and X-band SAR data: From algorithms to fully-automated flood services. In Proceedings of the Mapping Water Bodies from Space (MWBS), Frascati, Italy, 18-19 March 2015; Volume 46-47. 